\title{
Correlation and Analysis of Blowout Limits of Flames in High-Speed Airflows
}

\author{
James F. Driscoll* and Chadwick C. Rasmussen ${ }^{\dagger}$ \\ University of Michigan, Ann Arbor, Michigan 48109
}

\begin{abstract}
This work identifies a scaling parameter (which is a modified Damkohler number) that is found to correlate the flame blowout limits that were measured in six previous studies of nonpremixed flames which were stabilized in high-speed airflows by wall cavities, bluff bodies, and struts. Understanding the scaling of the combustor is needed to select the correct height of a cavity or step flameholder for ramjets, scramjets, or afterburners. This work focuses on nonpremixed conditions that occur when fuel is injected directly into a wall cavity or behind a strut, as is done with new designs. Thus, the Damkohler number that is identified is different from of that of Zukoski and Ozawa, who considered the different case of premixed flames in afterburners. Nonpremixed conditions introduce a new parameter that is not relevant for premixed conditions: the location of the fuel injector with respect to the recirculation zone. An analysis of a shear layer was performed in order to derive equations for the appropriate Damkohler number. Using this result, approximately 100 measured values of blowout limits from six previous studies were plotted, and a best-fit correlation curve that has a rich limit branch and a lean limit branch was determined. Although this correlation result provides a general estimate of blowout limits, it also indicates that additional research is needed to reduce the scatter in the correlation by improving the model of entrainment into the recirculation zone and by including unsteady effects. The results show that a reasonable correlation is achieved using the concept that the propagation speed of the flame in the shear layer is matched to the velocity of the local incident gas flow. Hot products in the recirculation zone preheat the shear-layer gases and increase the propagation speed of the flame. The analysis avoids an assumption that has been used previously-that the residence time of reactants in a "well-stirred" homogeneous reaction zone is matched to a global chemical reaction time. Experimental justification of the present approach is presented.
\end{abstract}

\section{Nomenclature}

$\begin{array}{lll}D a_{\mathrm{NP}}= & \begin{array}{l}\text { critical Damkohler number at flame blowout, } \\ \text { for nonpremixed conditions } \\ \end{array} \\ D a_{P} & =\begin{array}{l}\text { critical Damkohler number at flame blowout, } \\ \text { for premixed conditions [Eq. (1)] }\end{array} \\ f & =\text { mixture fraction (defined in Ref. 33) } \\ H & = & \text { step height (Fig. } 1) \\ h & = & \text { liftoff distance in } x \text { direction } \\ L_{\mathrm{RZ}} & = & \text { recirculation zone length } \\ M_{A} & = & \text { Mach number of airstream } \\ m_{A} & = & \text { characteristic air mass flow rate [Eq. (3)] } \\ m_{F} & = & \text { fuel mass flow rate } \\ R & = & \text { velocity ratio } U_{\mathrm{RZ}} / U_{A} \\ r_{S} & = & \text { stoichiometric fuel-air ratio } \\ S_{\mathrm{base}} & = & \text { propagation speed of base of the lifted flame } \\ S_{0} & = & \text { stoichiometric laminar burning velocity at } \\ & & 300 \mathrm{~K}, 1 \text { atm } \\ s & = & \text { density ratio } \rho_{\mathrm{RZ}} / \rho_{A} \\ T & = & \text { static temperature } \\ T_{F} & = & \text { fuel-injection temperature } \\ T_{0} & = & \text { stagnation temperature } \\ U & = & \text { axial velocity of gas } \\ W & = & \text { spanwise width of step } \\ x & = & \text { streamwise distance }\end{array}$

Presented as Paper 2004-3828 at the AIAA/ASME/SAE/ASEE 40th Joint Propulsion Conference, Ft. Lauderdale, FL, 11-14 July 2004; received 7 December 2004; revision received 25 April 2005; accepted for publication 26 April 2005. Copyright (C) 2005 by James F. Driscoll. Published by the American Institute of Aeronautics and Astronautics, Inc., with permission. Copies of this paper may be made for personal or internal use, on condition that the copier pay the $\$ 10.00$ per-copy fee to the Copyright Clearance Center, Inc., 222 Rosewood Drive, Danvers, MA 01923; include the code 0748-4658/05 \$10.00 in correspondence with the CCC.

*Professor, Department of Aerospace Engineering, 3004 FXB Building. Associate Fellow AIAA.

${ }^{\dagger}$ Research Assistant, Department of Aerospace Engineering, 2025 FXB Building. Member AIAA.

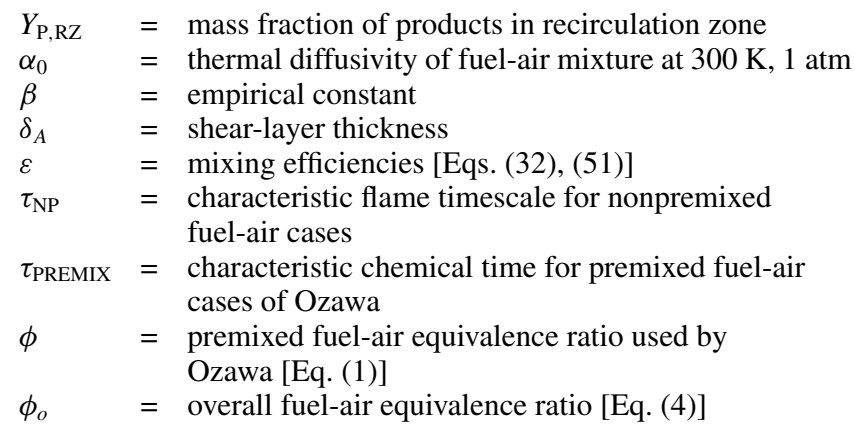

\section{Subscripts}

$A=$ air (freestream) side of shear layer

$F \quad=$ fuel side of shear layer

$\mathrm{RZ} \quad=$ recirculation zone

$s \quad=$ along stoichiometric contour just upstream of flame base

\section{Introduction}

$\mathbf{T}$ HIS research effort addresses the issue of how to properly scale combustor properties in high-speed propulsion devices that use directly fueled recirculation zones for flame stabilization. It is known that an important nondimensional scaling parameter is the Damkohler number, ${ }^{1-5}$ which can be used to relate the required step height $H$ in a laboratory device to that of a full-scale engine. Unfortunately, most existing theoretical and empirical relations for flame blowout only apply when the reactants are premixed, which commonly occurs in afterburners. However, in modern dualmode scramjets, the combustion is nonpremixed because fuel is injected directly into wall cavities ${ }^{6-12}$ or the wake of struts ${ }^{13,14}$ or bluff bodies. ${ }^{15-20}$ Nonpremixed combustion also occurs in other propulsion devices that use a "trapped vortex"21,22 or swirl ${ }^{23-25}$ for flame stabilization. Direct injection creates local fuel-rich and fuel-lean regions that are separated by near-stoichiometric "flammable zones." 
Previously, little work has been done to correlate nonpremixed flame blowout limits in high-speed devices. However, extensive work has been done for the premixed case; this work has been summarized by Zukoski and Marble ${ }^{1}$ and by Ozawa. ${ }^{2}$ Zukoski and Marble proposed that blowout occurs when the gas residence time in the shear layer equals the ignition delay time. If the premixed reactants are convected past the recirculation zone too quickly, the heat conducted from the hot recirculating gases will be insufficient to ignite the mixture. Ozawa later showed that the minimum step height $H$ is given by

$$
D a_{P}(\phi)=(H / U) / \tau_{\text {PREMIX }}=\exp \left[8.75(\phi-1)^{2}\right]
$$

$D a_{P}$ is the Damkohler number at blowout for premixed conditions; it is the ratio of a fluid mechanical time to a chemical time. $U$ is the freestream velocity, and $\tau_{\text {PREMIX }}$ is the characteristic chemical time for premixed fuel-air conditions. Equation (1) indicates that blowout in a large-scale device (i.e., for large values of $H$ and $U$ ) will occur at the same Damkohler number as in a small-scale device (for small values of $H$ and $U$ ), if both premixed devices have the same equivalence ratio $\phi$.

Ozawa $^{2}$ determined the characteristic time $\tau_{\text {PREMIX }}$ in Eq. (1) for premixed flames by plotting measured values of $H, U$, and $\phi$. Blowout data for kerosene fuel collapsed to the single curve given by Eq. (1) for the following chemical time:

$$
\tau_{\text {PREMIX }}=(0.21 \mathrm{~ms})\left[T_{0} / 300 \mathrm{~K}\right]^{-1.5}(p / 1 \mathrm{~atm})^{-1}\left(d / d_{e}\right)
$$

$T_{0}$ and $p$ are the stagnation temperature and static pressure of the freestream, and $d / d_{e}$ is a factor that varies between 1 and 2 for circular and V-shaped flameholder geometries. One can see from Eqs. (1) and (2) that a smaller step height can be used if one increases $T_{0}$, or $p$, or if one reduces $U$, or if the value of $\phi$ approaches unity.

Figure 1 is a plot of Eq. (1), which is named the Ozawa curve and is used to estimate the blowout limits of subsonic, premixed hydrocarbon-air flames in afterburners. Note that the horizontal axis is logarithmic, so that the function on the right side of Eq. (1) has the shape of a parabola. Unfortunately Eqs. (1) and (2) and Fig. 1 apply only to premixed flames because they assume that the combustion always occurs at the known equivalence ratio $\phi$ of the premixed reactants. Therefore, the goals of the present work were to 1) use concepts that apply to nonpremixed flames to derive a scaling relation analogous to Eq. (1) in which the Damkohler number appears; 2 ) identify nonpremixed flame timescale $\tau_{\mathrm{NP}}$ that applied for nonpremixed conditions and is analogous to the premixed chemical time given by Eq. (2); 3) plot measured blowout limits from six nonpremixed flame studies to determine if the nonpremixed flame timescale $\tau_{\mathrm{NP}}$ does allow the data to be correlated by single curve that is suggested by the analysis; and 4) use the analysis to identify sensitive parameters that need to be better quantified to improve the prediction of blowout limits.

Figure 2 shows the three different types of flameholders that were considered. A step, a wall cavity, and a strut all have three basic components: a shear layer, a recirculation zone, and an outer freestream

\section{premixed fuel-air}

equivalence ratio at blowout

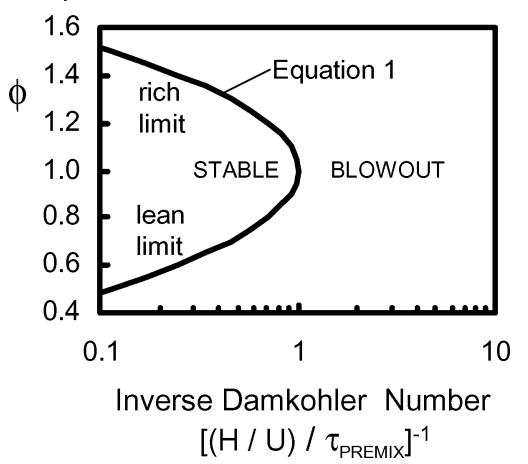

Fig. 1 Plot of the Ozawa curve ${ }^{2}$ [Eq. (1)], which correlates blowout limits of premixed subsonic flames.

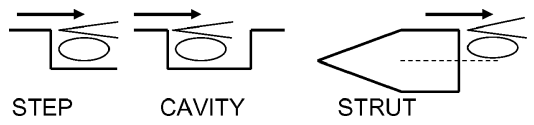

Fig. 2 Schematic showing that step, cavity, and strut flameholders consist of the same components: a shear layer located between the freestream and the recirculation zone.

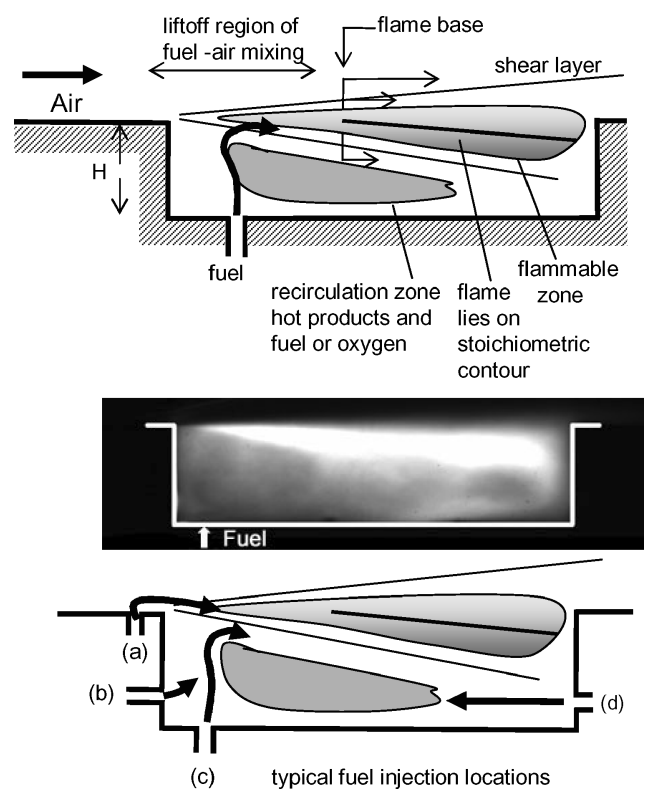

Fig. 3 Components of the shear layer in the nonpremixed flames considered and a photograph of the flame emission from Mach 2.0 supersonic cavity-stabilized flame of Ref. 12, showing that the flame is stabilized in the shear layer. A flammable zone exists between the airstream and the recirculation zone. The lower figure show several typical locations where fuel is injected.

of air. Figure 3 illustrates the locations where fuel is normally injected. In some cases the fuel is injected upstream of the step at location a so that the fuel enters directly into the shear layer. However, for other cases the fuel is injected directly into the recirculation zone at location $\mathrm{d}$. The injector location becomes an important new variable that does not appear in previous analyses ${ }^{3,4}$ of premixed flame blowout limits. For example, it has been observed ${ }^{9,21}$ that if fuel is injected directly into the recirculation zone at location $\mathrm{d}$, it is easier to "flood" the cavity with a fuel-rich mixture, forcing the flammable region to move upward and into the high-speed airstream. This tends to suppress the fuel-rich blowout limit (i.e., it limits the amount of fuel that can be injected before the flame blows out). If fuel is injected upstream of the step at location a, then much of the fuel can bypass the cavity. This tends to enhance the fuel-rich limit, but it suppresses the lean limit. If fuel is injected at location $b$, it also enters directly into the recirculation zone. Fuel that is injected at location $\mathrm{c}$ is observed ${ }^{9}$ to flow upward into the shear layer, as shown in Fig. 3.

Figure 3 also contains a photograph of the flame location for the supersonic cavity-stabilized flame studied in Ref. 12. This photo provides evidence that chemical reaction does not occur homogeneously throughout the recirculation zone, but that a localized reaction (a flame) exists in the shear layer near the top of the cavity. It is concluded from Fig. 3 that the flame is stabilized in the shear layer, and so we denote this condition as the shear-layer-stabilized flame regime. There are other possible regimes for which the flame instead is stabilized within the recirculation zone or at the fuel injector. Because flame stabilization was observed to occur in the shear layer in many instances for the conditions reported in Ref. 9, the shear-layer properties will be used to explain the present findings.

Figure 4 provides a physical explanation of the fuel-rich blowout limit. The rich limit is defined as the condition for which an excessive mass flow rate of fuel is injected, causing the flame to blowout. The solid line within the shear layer in Fig. 4a represents 

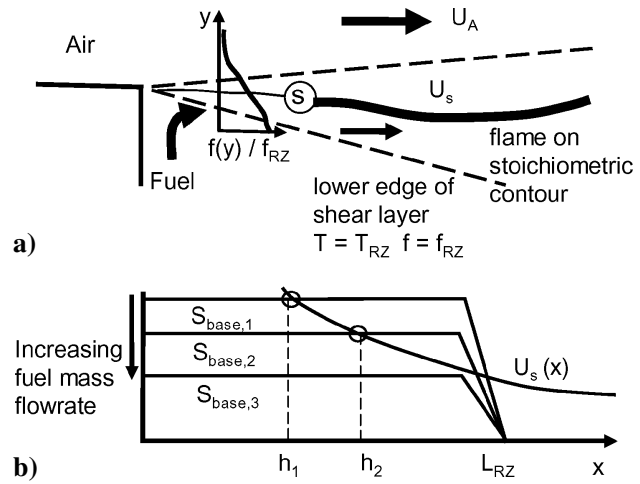

Fig. 4 Physical explanation of the rich blowout limit: a) heat transfer from hot products in the recirculation zone increases the temperature at lower edge of shear layer $T_{\mathrm{Rz}}$; b) increasing the fuel flow rate mixes cold fuel into the recirculation zone, reduces $T_{\mathrm{RZ}}$ and the flame propagation speed $S_{\text {base }}$ until it is less than the oncoming gas velocity, and so the liftoff height $h$ moves downstream.

the stoichiometric contour. Experiments ${ }^{26-29}$ have confirmed that a lifted nonpremixed jet flame is located along the stoichiometric contour. The curve labeled $U_{s}(x)$ in Fig. $4 \mathrm{~b}$ represents the gas velocity along that contour. Even though the fuel and air are initially nonpremixed, there will be local premixing in the liftoff region, which is represented by the thin line to the left of the location $\mathrm{s}$ marked in Fig. 4a. Studies of lifted subsonic jet flames ${ }^{27-29}$ have shown that the lifted flame base has a premixed flame character, and it propagates into the locally premixed mixture, even though most of the fuel is consumed in the downstream nonpremixed flame region. The horizontal lines labeled $S_{\text {base }}$ represent the propagation speed of the flame base. This propagation speed depends on the unburned gas temperature just upstream of the flame base, which is elevated because of heat transfer from the hot gases in the recirculation zone. The $x$ location where the curve of gas velocity $U_{s}$ crosses over the curve of propagation speed $S_{\text {base }}$ in Fig. $4 \mathrm{~b}$ is the liftoff height $h_{1}$. As the fuel flow rate is increased toward the rich limit, more cold fuel enters the recirculation zone, and so the fuel and products in the recirculation zone become cooler, then the gas temperature upstream of the flame base decreases. This causes the curves of propagation speed $S_{\text {base }}$ to decrease as shown. The liftoff distance $h$ shown in Fig. 4 b increases until it approaches $L_{\mathrm{RZ}}$ and the reactants are no longer preheated, and so rich blowout occurs. In addition, the stoichiometric contour is forced to move upwards into the higher velocity freestream, which is destabilizing.

\section{Correlation of Blowout Limits for Nonpremixed Flames}

To quantify the blowout limits, it is useful to define the overall fuel-air equivalence ratio of a nonpremixed flame $\phi_{o}$. It is not implied that this overall equivalence ratio is an indicator of any local equivalence ratio. Instead $\phi_{o}$ simply is defined such that when $\phi_{o}$ sufficiently exceeds one there is too much fuel injected, which causes the cavity to become flooded with fuel, forcing the stoichiometric contour up into the higher velocity region near the freestream, causing flame blowout at the rich limit. When $\phi_{o}$ is sufficiently less than one, not enough fuel is injected, and so a lean-limit blowout occurs. To define $\phi_{o}$, it is necessary to first define a characteristic air mass flow rate. The total mass flow rate of air contained in the freestream is not appropriate because this flow rate can be made arbitrarily large by increasing the height of the freestream above the recirculation zone, and this height is not a relevant parameter. Winterfeld ${ }^{6}$ and Kundu et al. ${ }^{4}$ present data showing that the air mass flow rate entrained into a recirculation zone behind a bluff body of height $H$ and width $W$ is proportional to $\rho_{A} U_{A} H W$. Therefore, following the convention set by Winterfeld, ${ }^{7}$ the characteristic air mass flow rate is defined as

$$
m_{A}=0.01 \rho_{A} U_{A} H W
$$

Thus, $m_{A}$ is $1 \%$ of the freestream airflow rate that would flow through an area equal to the product of the step height $H$ and width $W$. In this definition the value of $1 \%$ is chosen for convenience; it happens to cause the rich and lean limits to converge at an overall equivalence ratio of approximately unity, as shown next. The characteristic air mass flow rate defined by Eq. (3) is appropriate because it is proportional to the mass flow rate of air that is entrained into the shear layer, over the streamwise distance from $x=0$ to $L_{\mathrm{RZ}}$. Consider one side of a shear layer where the layer boundary is at a height $\delta_{A}$ above the layer centerline. The air mass flow rate crossing this boundary must be $\rho_{A} U_{A} \delta_{A} W$. Furthermore, $\delta_{A}$ is proportional to $L_{\mathrm{RZ}}$, which is proportional to the step height $H$ because the constant $L_{\mathrm{RZ}} / H$ is assumed to be known. It is noted that $m_{A}$ is used only for scaling purposes; it is not assumed that all of the air entrained into the shear layer is available for combustor or that it enters the recirculation zone. For an axisymmetric bluff body, the step height $H$ is defined as the radius of the bluff body, and the width $W$ is defined as the bluff-body circumference.

The overall equivalence ratio is defined as

$$
\phi_{o}=\left(m_{F} / m_{A}\right) r_{s}^{-1}
$$

The quantity $r_{s}$ is the stoichiometric fuel-air ratio, which has the value listed in the Appendix for several fuels. Note that for nonpremixed flames the combustion chemistry does not occur at the overall equivalence ratio $\phi_{o}$; instead, the flame tends to locate itself near the local stochiometric contour, as confirmed by experiments. $^{27-29}$ Varying $\phi_{o}$ only has an indirect effect on the chemistry; it can move the location of the stoichiometric contour farther from the hot recirculation zone, which lowers the temperatures of the gas entering the flame. The Damhohler number for the nonpremixed case is denoted $D a_{\mathrm{NP}}$ and is defined in a manner analogous to that of Ozawa ${ }^{2}$ :

$$
D a_{\mathrm{NP}}=\left(H / U_{A}\right) / \tau_{\mathrm{NP}}
$$

An important research issue is how to properly define the flame timescale $\tau_{\mathrm{NP}}$. The analysis of the next section suggests that $\tau_{\mathrm{NP}}$ should be

$$
\begin{aligned}
\tau_{\mathrm{NP}}= & \frac{\alpha_{0}}{S_{0}^{2}}\left[A \frac{\left(T_{\mathrm{AD}}-T_{0 A}\right)}{300 \mathrm{~K}} \frac{f_{s}}{2}+\frac{T_{0 A}}{300 \mathrm{~K}}\right]^{-2}\left(\frac{p}{1 \mathrm{~atm}}\right)^{-0.6} \\
& \times r_{s}^{-1}\left(\frac{H}{W}\right) \beta_{4}^{-1} \quad \text { at the lean limit } \quad \phi_{0}<1 \\
= & \frac{\alpha_{0}}{S_{0}^{2}}\left\{\left[B \frac{\left(T_{\mathrm{AD}}-T_{F}\right)}{300 \mathrm{~K}}+\frac{\left(T_{F}-T_{0 A}\right)}{300 \mathrm{~K}}\right] C+\frac{T_{0 A}}{300 \mathrm{~K}}\right\}^{-2} \\
& \times\left(\frac{p}{1 \mathrm{~atm}}\right)^{-0.6} D^{-1} \quad \text { at the rich limit } \quad \phi_{0}>1
\end{aligned}
$$

and

$$
\begin{gathered}
A=\left[1+\beta_{3}\left(L_{\mathrm{RZ}} / H\right) r_{s}^{-1} \phi_{o}^{-1}\right]^{-1} \\
B=\left[1+\beta_{1}\left(H / L_{\mathrm{RZ}}\right) r_{s} \phi_{o}\right]^{-1} \\
C=f_{s}[1-B]^{-1} \quad D=\left(L_{\mathrm{RZ}} / H\right)(1-C)^{-1} \phi_{o} \beta_{2}
\end{gathered}
$$

$S_{0}$ and $\alpha_{0}$ are the stoichiometric laminar burning velocity and the mass diffusivities of the mixture at $1 \mathrm{~atm} 300 \mathrm{~K}$. $T_{\mathrm{AD}}$ is the adiabatic flame temperature listed in Table 1 , and $T_{0 A}$ is the air stagnation temperature. The ratio $L_{\mathrm{RZ}} / H$ is a known constant that has been measured $^{6}$ to be approximately two for a bluff body. For a wall cavity it approximately equals the cavity length to height ratio. Values of the stoichiometric mixture fraction $f_{s}$ are listed in the Appendix. The four quantities $\beta_{1}, \beta_{2}, \beta_{3}$, and $\beta_{4}$ are empirical constants. 
Table 1 Examples of some flame blowout limits reported previously

\begin{tabular}{|c|c|c|c|c|c|c|c|c|c|c|}
\hline References & Mach number & Fuel & $H$, step ht., mm & $D a$ & $T_{0 A}, \mathrm{~K}$ & $U_{A}, \mathrm{~m} / \mathrm{s}$ & $m_{F}, \mathrm{~g} / \mathrm{s}$ & $m_{A}, \mathrm{~g} / \mathrm{s}$ & $\phi_{o}$ & Limit \\
\hline Winterfeld $^{7}$ & 2.1 & $\mathrm{H}_{2}$ & 10 & 3.48 & 375 & 530 & 0.40 & 4.00 & 3.45 & Rich \\
\hline Bluff body & 2.1 & $\mathrm{H}_{2}$ & 10 & 1.22 & 375 & 610 & 0.09 & 4.60 & 0.69 & Lean \\
\hline Rasmussen et al. ${ }^{9}$ & 2.0 & $\mathrm{C}_{2} \mathrm{H}_{4}$ & 17 & 3.92 & 590 & 711 & 1.98 & 9.16 & 3.18 & Rich \\
\hline Wall cavity & 2.0 & $\mathrm{C}_{2} \mathrm{H}_{4}$ & 17 & 1.23 & 590 & 711 & 0.35 & 6.70 & 0.77 & Lean \\
\hline Niioka et al. ${ }^{13}$ & 1.5 & $\mathrm{H}_{2}$ & 7.5 & 5.7 & 500 & 546 & 0.56 & 1.80 & 10.7 & Rich \\
\hline Strut & 1.5 & $\mathrm{H}_{2}$ & 7.5 & 3.5 & 500 & 546 & 0.27 & 1.61 & 5.8 & Rich \\
\hline Gruber et al. ${ }^{10}$ cavity & 2.0 & $\mathrm{C}_{2} \mathrm{H}_{4}$ & 17 & 1.89 & 590 & 711 & 0.33 & 8.60 & 0.56 & Lean \\
\hline Schefer et al. ${ }^{17}$ & 0.3 & $\mathrm{CH}_{4}$ & 25 & 1.02 & 296 & 105 & 0.26 & 5.00 & 0.9 & Lean \\
\hline
\end{tabular}

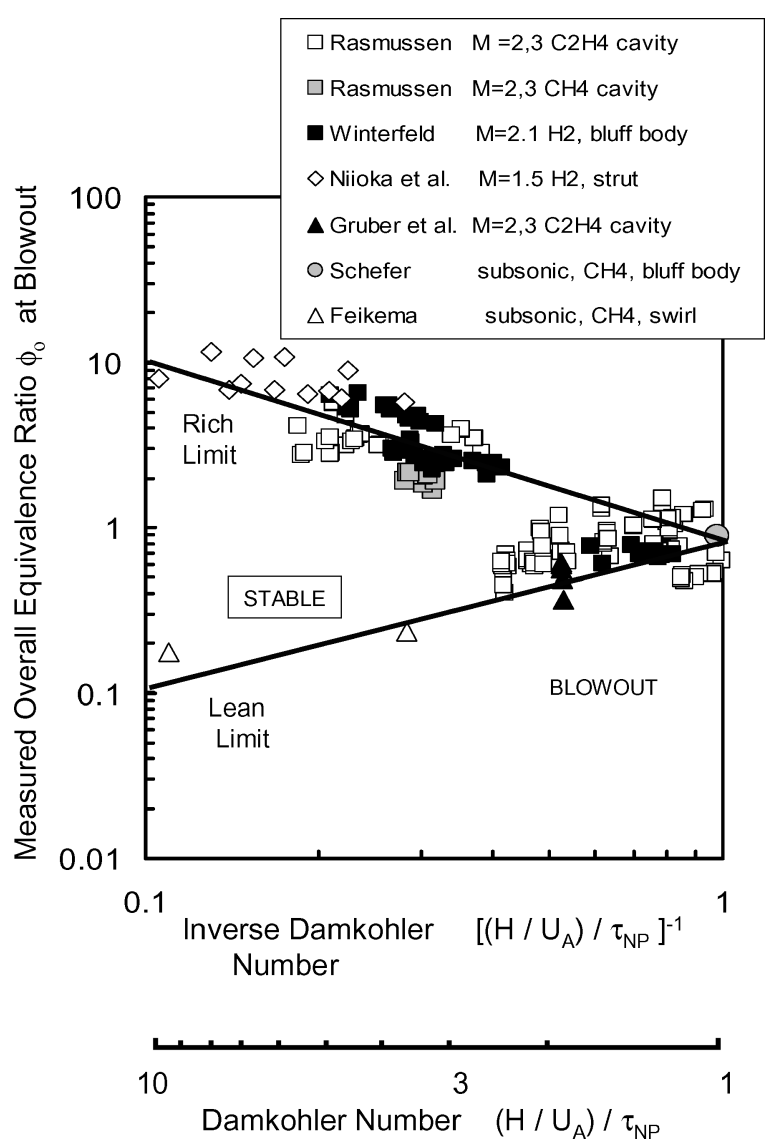

Fig. 5 Correlation of measured rich and lean blowout limits from six nonpremixed flame studies compared to Eqs. (7) and (8) (-), using the proposed nonpremixed chemical time $\tau_{\mathrm{NP}}$.

To assess the validity of Eqs. (5-9), approximately 100 values of flame blowout limits first were tabulated from the results of six previous studies of nonpremixed flames. ${ }^{7,9,10,13,17,23}$ Table 1 lists several of the values of the blowout limits. Then a plot that is similar to the form of the Ozawa plot was generated; the overall equivalence ratio $\phi_{o}$ was plotted against the inverse of the Damkohler number that is defined by Eq. (5). Each of the four empirical constants $\left(\beta_{1}-\beta_{4}\right)$ in Eqs. (6-9) was set to an optimum value to determine if the measurements can be correlated and represented by Eqs. (5-9).

Figure 5 shows the results of the effort to correlate the rich and lean blowout limits. The vertical axis represents the overall equivalence ratio defined by Eqs. (3) and (4), and the horizontal axis represents the inverse of the Damkohler number. Values plotted in Fig. 5 include measurements reported for supersonic bluff-body stabilizers and hydrogen fuel by Winterfeld ${ }^{7}$ (Fig. 14). Supersonic cavity-stabilized flame blowout limits were measured by Rasmussen et al. ${ }^{9,12}$ and Gruber et al., ${ }^{10}$ who used ethylene fuel. Supersonic dual struts and hydrogen fuel were used by Niioka et al. ${ }^{13}$ (Figs. 3 and 4). Also shown in Fig. 5 are results for the subsonic bluff-body hydrocarbon flames of Schefer et al. ${ }^{17}$ and Feikema et al. ${ }^{23,24}$ The lean
Table 2 Values chosen for the four empirical constants in Eqs. (6-8) [Injector location (Fig. 3)]

\begin{tabular}{lccc}
\hline \hline & \begin{tabular}{c}
$\mathrm{A}, \mathrm{C}=$ fuel \\
\cline { 2 - 2 } Empirical constant
\end{tabular} & $\begin{array}{c}\text { Injected into } \\
\text { shear-layer }\end{array}$ & $\begin{array}{c}\mathrm{B}, \mathrm{D}=\text { fuel } \\
\text { recirculation zone }\end{array}$ \\
\hline$\beta_{1}$ Rich limit & 5 & 4 \\
$\beta_{2}$ Rich limit & 0.025 & 0.025 \\
$\beta_{3}$ Lean limit & 0.002 & 0.004 \\
$\beta_{4}$ Lean limit & 1.0 & 1.0 \\
\hline \hline
\end{tabular}

and rich blowout limits are defined to occur when the fuel mass flow rate is either decreased or increased sufficiently to cause flame blowout. The values of the four empirical constants $\beta_{1}$ to $\beta_{4}$ are listed in Table 2. $\beta_{1}$ is shown to be proportional to the fraction of fuel entrained into the shear layer, so that the value of $\beta_{1}$ is larger when the fuel is injected directly into the shear layer from locations $\mathrm{A}$ and $\mathrm{C}$ that are identified in Fig. 3. $\beta_{3}$ is proportional to the fraction of fuel entrained into the recirculation zone, so that the value of $\beta_{3}$ is larger when fuel is injected directly from locations B and D.

It is observed that most of the measurements plotted in Fig. 5 are clustered about the two solid lines, which are represented by

$$
\begin{aligned}
& D a_{\mathrm{NP}}^{-1}=\phi_{o} \quad \text { for the lean limit } \quad \phi_{0}<1 \\
& =\phi_{o}^{-1} \quad \text { for the rich limit } \quad \phi_{0}>1
\end{aligned}
$$

Note that the upper solid line in Fig. 5 (the rich limit) has a slope of -1 , and the lower solid line (the lean limit) has a slope of +1 . These two solid lines represent the formulas that are derived in the next section. Therefore it is concluded that the scaling parameter $\tau_{\mathrm{NP}}$ that is suggested by our analysis does adequately correlate the data in Fig. 5. Of course this is an empirical correlation because the four constants $\beta_{1}-\beta_{4}$ were selected to optimize the curve fit. However Eqs. (5-11) represent a useful way to estimate the step height $H$ required to stabilize nonpremixed flames.

The scatter of the data in Fig. 5 is believed to be caused by several factors. First, it is predicted by Eqs. (5) and (6) and by previous researchers ${ }^{2-5}$ that if the type of fuel is changed the step height required should scale as the inverse square of the burning velocity $S_{0}$. Therefore, if hydrogen fuel is replaced with methane, which burns six times slower than hydrogen, the minimum step height is expected to be 36 times larger. Although methane flames are found to be less stable than hydrogen flames, this predicted factor of 36 is larger than the factor that is measured, for reasons that are not understood. A second source of scatter in Fig. 5 is that the complex entrainment of hot products and fuel into the recirculation zone is not sufficiently understood. Factors that can affect entrainment that were not considered include the effect of the flame on the entrainment, the molecular weight of the fuel, and various details about the fuelinjection process. In the analysis of the next section, it is assumed that the flame is stabilized in the shear layer. This is usually a good assumption, based on the images in Ref. 12, but in some cases this assumption might be violated, which can cause some of the scatter in Fig. 5. Additional research is needed to better quantify the unsteady entrainment process and the details of the flow near the injectors. 


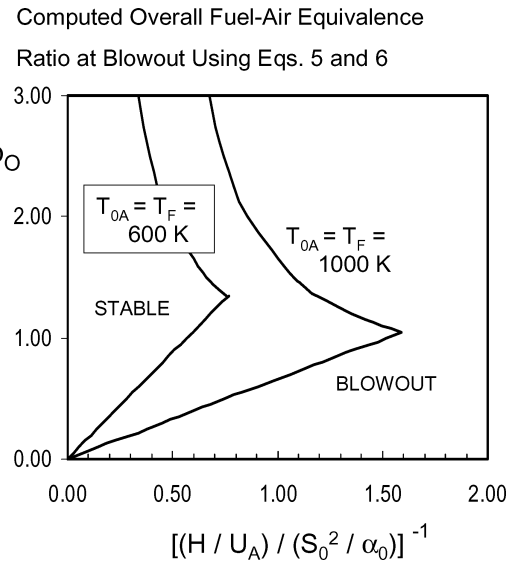

Fig. 6 Plot of Eqs. (5-9) showing that the stable regime becomes larger as the stagnation temperature of the air is increased. These curves are similar to the measured curves in Ref. 15 . Fuel $=$ hydrogen; $p=1 \mathrm{~atm}$, $L_{\mathrm{RZ}} / H=2.0$, and $W / H=6$.

Figure 6 provides additional evidence that the proposed chemical time is realistic. Blowout limits were calculated using Eqs. (5-9) for two air stagnation temperatures: 600 and $1000 \mathrm{~K}$. The fuel is hydrogen, and the fuel-injection temperatures are equal to the air stagnation temperatures. Note that no chemical time appears on the horizontal axis, and so the two curves that are plotted are not expected to collapse to a single curve. The calculated rich and lean blowout limits merge at a value of $\phi_{o}$ of approximately unity, and increasing the stagnation temperature causes the curves to shift to the right, leading to a larger range of stable conditions. Previously, Yoon et al. ${ }^{15}$ reported blowout measurement on a plot that was similar to Fig. 6, and the shape of the measured curves is in agreement with those seen in Fig. 6.

\section{Effect of Fuel Injection Location}

Inspection of the data reported by Rasmussen et al. ${ }^{9}$ indicates some differences between fuel injection at the cavity floor location (c in Fig. 3) and at location d, which is on the downstream wall of the cavity. Injecting fuel from floor location c forces fuel to go directly upward into the shear layer, so that much of the fuel will be transported over the cavity and will not enter the downstream region of the recirculation zone. Therefore, large fuel flow rates injected at c will not flood the cavity with fuel. However, large fuel flow rates injected at location d will go directly into the recirculation zone and will flood the cavity with fuel. Consistent with this idea, the rich blowout limits of Ref. 9 are observed to be larger for injection at location $\mathrm{c}$ than at $\mathrm{d}$.

To account for these observations, the constant $\beta_{3}$ in Eq. (7) should be smaller when fuel is injected at $\mathrm{c}$ than at $\mathrm{d}$ because the following analysis indicates that $\beta_{3}$ is proportional to the fraction of fuel that is entrained into the recirculation zone, rather than into the shear layer. Therefore $\beta_{3}$ was chosen to be 0.002 for injection location $\mathrm{c}$ and 0.004 for location $d$. These values provide the best fit to the data to Eqs. (10) and (11).

\section{Comparison of Nonpremixed and Premixed Flame Blowout Limits}

It is observed that the curve in Fig. 5 that correlates nonpremixed flame blowout limits has the same general appearance as the Ozawa curve (Fig. 1) for premixed flames. In both figures the measurements collapse to a curve that reaches a maximum value of $D a^{-1}$ at an equivalence ratio of approximately one. Another similarity is that both the premixed and nonpremixed chemical times decrease as one increases the stagnation temperature or the static pressure of the freestream, as indicated by Eqs. (2), (6a), and (6b). This is expected because a smaller chemical time should cause the flame to become more stable.

Several major differences between nonpremixed and premixed blowout limits can be seen by comparing the flame timescales given by Eqs. (2) and (6). The location where the fuel is injected is important in the nonpremixed case [and it affects the parameters $\beta_{2}$ and $\beta_{3}$ in Eqs. (7) and (9) and Table 2], but the location of fuel injection is not relevant to the premixed case. The stoichiometric mixture fraction $f_{s}$ plays an important role in the nonpremixed case because it appears in Eqs. (6a) and (9), but it does not appear in the premixed flame timescale [Eq. (2)]. For example, a nonpremixed hydrogenair flame must lie close to the region where the mixture is $97.1 \%$ air and $2.9 \%$ fuel by mass $\left(f_{s}=0.029\right)$. The location of a premixed flame depends on a different parameter-its burning velocity.

Another difference is that the temperatures of the fuel and air appear as separate terms in Eqs. (6a) and (6b) because they can be injected with different temperatures in the nonpremixed case, but not in a premixed situation. The definition of equivalence ratio also differs; for the premixed case $\phi$ is proportional to the actual amount of fuel that is locally mixed with air, and so $\phi$ controls the local chemistry. For the nonpremixed case $\phi_{o}$ simply indicates the mass flow of fuel relative to that of air; the chemistry is not required to occur at a local equivalence ratio equal to $\phi_{o}$. For these reasons the Ozawa relation [Eq. (1)] should not be applied to nonpremixed flames.

\section{Derivation of the Nonpremixed Flame Timescale $\tau_{\mathrm{NP}}$ for the Rich Blowout Limit}

In this section a formula for the nonpremixed flame timescale $\tau_{\mathrm{NP}}$ is derived using shear-layer similarity concepts. The following simplifying assumptions were made:

1) Upstream of a lifted flame base there exists a flammable zone in the shear layer between the fuel-rich and fuel-lean layers, and a stoichiometric contour exists. Experimental evidence that the flammable zone exists upstream of a lifted nonpremixed jet flame is provided by Refs. $27-29$.

2) The fundamental assumption for flame stability ${ }^{30}$ is that even though the fuel and air initially are nonpremixed, they mix in the nonreacting liftoff region so that the flame base is a premixed flame that propagates at a velocity $S_{\text {base }}$ which is equal to the gas velocity along the stoichiometric contour $U_{s}$; thus,

$$
S_{\text {base }}\left(T_{s}\right)=U_{s}
$$

The location $s$ is marked in Fig. $4 \mathrm{a} ; U_{s}$ is the gas velocity at that location. $S_{\text {base }}$ is a function of the temperature $T_{s}$ of the reactants just upstream of the flame base, and the reactants are heated by heat transfer from the recirculation zone. Experimental verification of Eq. (12) is provided by Upatnieks et al. ${ }^{31}$ and Muniz and Mungal. ${ }^{32}$ Another requirement for stability is that

$$
\frac{\mathrm{d}\left(S_{\text {base }}\right)}{\mathrm{d} x}>\frac{\mathrm{d}\left(U_{s}\right)}{\mathrm{d} x}
$$

This requirement ensures that if the flame is perturbed to move downstream, at the new location the propagation speed will exceed the local gas velocity, so that the flame will propagate back to its original location.

3) Rich blowout is observed in experiments ${ }^{9}$ to occur when the fuel mass flow rate is increased sufficiently to force the flame liftoff distance $h$ to move sufficiently far downstream. This observation suggests that the gas upstream of the flame base is heated by heat transfer from the recirculation zone, and this heat transfer is diminished when $h$ approaches $L_{\mathrm{Rz}}$. Based on these experimental observations, it is assumed that rich blowout occurs when the liftoff distance $h$ equals

$$
h=L_{\mathrm{RZ}} \quad \text { rich blowout }
$$

It is understood that blowout might occur when $h$ is some fraction of $L_{\mathrm{RZ}}$, rather than exactly equal to $L_{\mathrm{RZ}}$. However it is sufficient to use a constant of proportionality of 1.0 in our scaling analysis because this constant becomes part of another constant that is determined empirically.

4) It is assumed that the flame base always is located within the shear layer and not within the recirculation zone for the cases 
considered. The stoichiometric fuel-air ratio for hydrocarbon and hydrogen fuels does not exceed 0.07 ; thus, the stoichiometric contour is forced to be relatively close to the airstream where the local fuel-air ratio is zero. Measurements by Winterfeld ${ }^{6,7}$ and by Kalt et al. ${ }^{33}$ indicate that the recirculation zone is filled with either hot products and fuel (near the rich blowout limit) or hot product and air (near the lean limit), but the measurements do not indicate that fuel and air are present simultaneously. Kalt et al. ${ }^{33}$ also showed that the flammable zone (where significant oxygen exists) occurs only in the shear layer between the recirculation zone and the airstream. Images of supersonic flames in Ref. 12 indicate that normally the flame is stabilized in the shear layer. However, in some cases in Ref. 12 the flame exists within the recirculation region, and it is not clear where it is stabilized. We will only consider cases for which the flame is stabilized in the shear layer.

5) It is assumed that blowout is not governed by the requirement that the fluid residence time in the recirculation zone is matched to some chemical reaction time, which has been assumed in the past $^{3}$ for premixed flames. This previous idea assumed that a distributed reaction zone exists instead of a flame. Instead, images of Ratner et al. ${ }^{34}$ confirm that thin flames exist and not distributed reaction zones for intensely turbulent nonpremixed conditions. They report images of very thin $\mathrm{CH}$ layers (that are less than $1 \mathrm{~mm}$ thick) that lie within the shear layer (between a recirculation zone and the airstream), and they see no evidence of distributed reaction zones.

6) In the liftoff region of the shear layer (upstream of any chemical reaction), it is assumed that there is similarity between the profiles of mixture fraction $f$, stagnation temperature $T_{0}$, and gas velocity $U$, such that

$$
\frac{f(y)}{f_{\mathrm{RZ}}}=\frac{T_{0}(y)-T_{0 A}}{T_{0, \mathrm{RZ}}-T_{0 A}}=\frac{U_{A}-U(y)}{U_{A}-U_{\mathrm{RZ}}}
$$

This similarity relation arises because the equations that represent the conservation of mixture fraction, enthalpy, and momentum are identical if the axial pressure gradient is small and the Lewis number and Schmidt number are unity. Even if a portion of the shear layer is supersonic, Papaposchou and Roshko ${ }^{35}$ have shown that the shear layer exhibits self-similarity. A typical profile of $f(y) / f_{\mathrm{RZ}}$ is shown in Fig. 4. All three of the quantities equated in Eq. (15) have a value of zero on the upper (air) side of the shear layer and have a value of one on the lower (recirculation zone) side. Some justifications for the preceding assumptions are provided by images of the flame chemiluminescence reported by Rasmussen et al. ${ }^{12}$ for the cavitystabilized Mach 2.0 ethylene-air supersonic flame of Ref. 9. One such image appears in the center of Fig. 3. The flame base is observed in Fig. 3 to lie in the shear layer. As the fuel flow rate is increased near the rich limit, it was observed that the flame base moves downstream. Near the lean limit, as the fuel flow rate is decreased, the flame base moves upstream. This observation is consistent with the preceding assumptions 3 and 4 .

Based on the preceding six assumptions, the problem reduces to that of a flame that is stabilized in a stratified shear layer. The boundary conditions on the air side are uniform and known $\left(U=U_{A}\right.$, $T_{0}=T_{0 A}, f=0$ ). On the lower side of the shear layer, the boundary conditions depend on the entrainment into the recirculation zone. We choose to define the lower edge of the shear layer as the location where the axial velocity is zero. Thus the lower part of the shear layer overlaps the upper portion of the recirculation zone. At this lower edge, $T=T_{\mathrm{RZ}}$, and $f=f_{\mathrm{RZ}}$. In the recirculation zone it is assumed that near the rich limit there is a uniform mixture of fuel and products. Kalt et al. ${ }^{33}$ used Raman diagnostics and showed that the recirculation zone contains a fuel-product mixture that is very uniform in space, except at locations close to the flame. Therefore $T_{\mathrm{RZ}}$ and $f_{\mathrm{RZ}}$ can be assumed to be nearly uniform throughout the recirculation zone.

To use the fundamental flame stability criterion [Eq. (12)], it is necessary to determine the gas velocity $U_{s}$ and the temperature $T_{s}$ just upstream of the flame base. Consider the case of a simple jet flame ${ }^{36-38}$ : the profiles of $U / U_{0}$ and mixture fraction $f$ should be equal everywhere because of the similarity between the conservation equations for these two quantities. $U_{0}$ is the jet-exit velocity. Along the stoichiometric contour $U=U_{s}$ and $f=f_{s}$, so that in a jet flame

$$
U_{s}=U_{0} f_{s} \Gamma
$$

where $\Gamma$ is a factor that accounts for gas expansion caused by the flame, which causes streamlines to diverge. ${ }^{36-38}$ An adequate explanation of measured liftoff heights of jet flames is obtained by setting $\Gamma$ equal to $c_{1}(\delta / x)$, where $c_{1}$ is a constant and $\delta$ is the flame thickness $\alpha_{0} / S_{0}$. When this value of $\Gamma$ is inserted into Eq. (16) and the value of $x$ is set equal to $h$, one obtains the well-known relation for the liftoff height of a jet flame [Eq. (4) in Ref. 39]:

$$
h=\frac{c_{1} U_{0} f_{s}}{\left(S_{0}^{2} / \alpha_{0}\right)}
$$

The blowout limit of a jet flame is determined by the criterion ${ }^{30,40}$ that the liftoff height cannot exceed the length of the flammable zone of the jet, which is $\left(c_{2} d\right)$, where $d$ is the jet diameter and $c_{2}$ is a constant. Equating this length to the liftoff height given by Eq. (15) yields a jet flame blowout velocity of

$$
U_{0}=d\left(S_{0}^{2} / \alpha_{0}\right)\left(c_{2} / c_{1}\right) / f_{s}
$$

which has been verified by measurements made in jet flames. ${ }^{40}$

Now consider the cavity-stabilized flame, which has the stratified shear layer shown in Fig. 3. We solve Eq. (15) for $U$ and set $U=U_{s}$, $f=f_{s}$, and $U_{\mathrm{RZ}}=0$ at the lower edge of the shear layer, to obtain

$$
U_{s}=U_{A}\left(1-f_{s} / f_{\mathrm{RZ}}\right) \Gamma
$$

$\Gamma$ is a factor that accounts for gas expansion caused by a flame; we assume that $\Gamma$ has the same value $\left(c_{1} \delta / x\right)$ as was used above for a jet flame. Combining Eqs. (12) and (19) and setting $x=h, \delta=\alpha / S_{\text {base }}$ leads to

$$
S_{\text {base }}=U_{A}\left(1-f_{s} / f_{\mathrm{RZ}}\right)\left(c_{1} \alpha / S_{\text {base }}\right) / h
$$

After applying our blowout criterion that $h=L_{\mathrm{RZ}}$ [Eq. (14)], rearrangement yields a relation for the minimum step height $H$ to stabilize the flame

$$
\begin{aligned}
& \left(H / U_{A}\right) /\left(\alpha_{0} / S_{0}^{2}\right)=\left(L_{\mathrm{RZ}} / H\right)^{-1} \\
& \quad \times\left[S_{\text {base }} / S_{0}\right]^{-2}\left[\alpha / \alpha_{0}\right]\left(1-f_{s} / f_{\mathrm{RZ}}\right) c_{1}
\end{aligned}
$$

$\left(L_{\mathrm{RZ}} / H\right)^{-1}$ is a constant for a particular geometry, and $S_{0}$ and $\alpha_{0}$ are the reference values of the stoichiometric laminar burning velocity and thermal diffusivity at $300 \mathrm{~K}$ and $1 \mathrm{~atm}$. It is assumed that the ratio of the turbulent burning velocity to the laminar burning velocity $\left(\mathrm{S}_{T} / S_{L}\right)$ is a constant, so that the velocity of the flame base can be written:

$$
S_{\text {base }} / S_{0}=\left(S_{T} / S_{L}\right)\left(S_{L} / S_{0}\right)
$$

The laminar burning velocity $S_{L}$ depends on the temperature and pressure of the reactants according to ${ }^{41-43}$

$$
S_{L} / S_{0}=\left(T_{s} / 300 \mathrm{~K}\right)^{1.75}(p / 1 \mathrm{~atm})^{-0.2}
$$

where $S_{0}$ is the laminar burning velocity at $300 \mathrm{~K}, 1$ atm. The exponents in Eq. (22) represent an average of values reported in Refs. 4143. The thermal diffusivity $\alpha$ also depends on temperature according to

$$
\alpha / \alpha_{0}=\left(T_{s} / 300 \mathrm{~K}\right)^{1.5}(p / 1 \mathrm{~atm})^{-1}
$$

Inserting Eqs. (22) and (23) into Eq. (21) leads to

$$
\left(\frac{H / U_{A}}{\alpha_{0} / S_{0}^{2}}\right)=\left[\frac{T_{S}}{300 \mathrm{~K}}\right]^{-2}\left(\frac{p}{1 \mathrm{~atm}}\right)^{-0.6}\left(1-\frac{f_{s}}{f_{\mathrm{RZ}}}\right)\left(\frac{L_{\mathrm{RZ}}}{H}\right)^{-1} c_{1}^{\prime}
$$


where the constant $c_{1}^{\prime}$ is $c_{1}\left(S_{T} / S_{L}\right)^{-2}$. To determine the temperature $T_{s}$ just upstream of the flame base, which appears in Eq. (24), we solve Eq. (15) for $T_{0}$ and set it equal to $T_{s}$ at the location where we also set $f=f_{s}$. This assumes that at the stoichiometric contour the stagnation and static temperatures are nearly equal. Equation (15) is reduced to

$$
T_{s}=T_{0 A}+\left(f_{s} / f_{\mathrm{RZ}}\right)\left(T_{\mathrm{RZ}}-T_{0 A}\right)
$$

The temperature in the recirculation zone $T_{\mathrm{RZ}}$ depends on the mass fraction of products $Y_{\mathrm{P}, \mathrm{RZ}}$, which coexist with fuel near the rich limit. It is assumed that there is no reaction occurring in the recirculation zone (reactions only occur in the shear layer), so that we consider the mixing of two streams in the recirculation zone: hot products at temperature $T_{\mathrm{AD}}$ and cold fuel at temperature $T_{F}$. Enthalpy conservation requires that

$$
c_{P} T_{\mathrm{RZ}}=Y_{\mathrm{P}, \mathrm{RZ}} c_{P} T_{\mathrm{AD}}+\left(1-Y_{\mathrm{P}, \mathrm{RZ}}\right) c_{P} T_{F}
$$

where heat capacity is $c_{P}$. Combining Eqs. (25) and (26) yields

$$
T_{s}=T_{0 A}+\left(f_{s} / f_{\mathrm{RZ}}\right)\left[Y_{\mathrm{P}, \mathrm{RZ}}\left(T_{\mathrm{AD}}-T_{F}\right)+\left(T_{F}-T_{0 A}\right)\right]
$$

The problem has been reduced to that of determining the mass fraction of products in the recirculation zone $Y_{\mathrm{P}, \mathrm{RZ}}$. The adiabatic flame temperature $T_{\mathrm{AD}}$ and initial fuel and air temperatures $T_{F}, T_{0 A}$ in Eq. (27) are given.

\section{Parameters That Characterize Entrainment}

The analysis leading to Eq. (27) indicates that an important parameter is the mass fraction of the product that is entrained into the recirculation zone $Y_{\mathrm{P}, \mathrm{RZ}}$, which controls the gas temperature in the recirculation zone. Although it is not possible to calculate entrainment rates accurately, we instead will use the scaling relations that have been measured by Winterfield, ${ }^{6}$ Bovina, ${ }^{20}$ and Slessor et al. ${ }^{44}$ that characterize the entrainment into recirculation zones and shear layers. First consider the entrainment of air into the shear layer shown in Fig. 7, which has a height $\delta_{A}$ at the downsteam end of the wall cavity. The mass flow rate of air that is entrained into a supersonic shear layer $m_{\mathrm{A}, \mathrm{SH}}$ over a streamwise distance $x$ has been reported by Slessor et al. ${ }^{44}$ to be

$$
m_{\mathrm{A}, \mathrm{SH}}=\left(\delta_{\mathrm{A}} / x\right) \rho_{A} U_{A} W x
$$

where

$$
\frac{\delta_{A}}{x}=\left(\frac{c_{\delta}}{2}\right) \frac{(1-R)\left(1+s^{\frac{1}{2}}\right)}{\left(1+s^{\frac{1}{2}} R\right)}\left\{1-\frac{\left(1-s^{\frac{1}{2}}\right) /\left(1+s^{\frac{1}{2}}\right)}{1+2.9(1+R) /(1-R)}\right\}\left(\frac{\delta_{A}}{\delta_{0}}\right)
$$

Equation (29a) can be simplified because the shear layer shown in Fig. 7 has density ratio $\left(s=\rho_{\mathrm{RZ}} / \rho_{A}\right)$ that is approximately zero because the density of the hot gas in the recirculation zone is assumed to be much less than the density of the airstream. Similarly, the velocity ratio $\left(R=U_{\mathrm{RZ}} / U_{A}\right)$ also is approximately zero because on the lower side of the shear layer is defined to be where the streamwise gas velocity is zero. Reference 44 (Fig. 2) indicates that the compressibility term $\left(\delta_{A} / \delta_{0}\right)$ is approximately equal to 0.2 over the Mach-number range from 0.8 to 3 and the constant $c_{\delta}$ is 0.35 . With these values, Eq. (29a) becomes

$$
\delta_{A} / x=0.026
$$

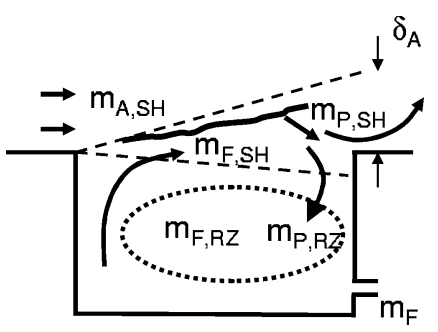

Fig. 7 Schematic of several hypothetical paths that the fuel, the product, and the air could follow, leading to the entrainment of fuel and products into the recirculation zone near the rich blowout limit.
Because $m_{\mathrm{A}, \mathrm{SH}}$ is the mass per second of air entrained into the shear layer from $x=0$ to $L_{\mathrm{RZ}}$, we set $x$ in Eq. (28) equal to $L_{\mathrm{RZ}}$, and combine Eqs. (28) and (29b) to obtain

$$
m_{\mathrm{A}, \mathrm{SH}}=0.026 \rho_{A} U_{A} W L_{\mathrm{RZ}}
$$

Now we consider the entrainment of mass into a recirculation zone; the appropriate scaling relation was measured by Bovina ${ }^{20}$ and later by Winterfeld ${ }^{6}$ to be

$$
m_{\mathrm{A}, \mathrm{RZ}}=K \rho_{A} U_{A} W L_{\mathrm{RZ}}
$$

where $K$ is an entrainment constant that varied between 0.010 and 0.025 . To measure this relation, both Bovina and Winterfeld filled a recirculation zone behind a bluff body with a tracer gas (sodium vapor and boron fluoride, respectively). The tracer flow was suddenly discontinued, and the rate at which the tracer light signal decayed in time was measured. This indicated the rate at which dilution air was entrained. Note that these previous experiments show that the mass flow rate that is entrained into a recirculation zone [Eq. (30b)] is proportional to the mass flow rate, which is entrained into the shear layer [Eq. (30a)].

We now use the entrainment rate formulas [Eqs. (30a) and (30b)] from Refs. 6, 20, and 44 to determine scaling relations for the gas composition of the recirculation zone. Figure 7 is a schematic that shows that a portion of the total fuel flow rate and a portion of the total product flowing away from the flame enter the recirculation zone. Near the rich blowout limit only fuel and products mix in the recirculation zone, and so conservation of product mass requires that the total mass flow into the recirculation zone $m_{\mathrm{RZ}}$ is the sum of the flow rates of products and fuel that enter

$$
m_{\mathrm{RZ}}=m_{\mathrm{P}, \mathrm{RZ}}+m_{\mathrm{F}, \mathrm{RZ}}
$$

thus,

$$
Y_{\mathrm{P}, \mathrm{RZ}}=m_{\mathrm{P}, \mathrm{RZ}} / m_{\mathrm{RZ}}=m_{\mathrm{P}, \mathrm{RZ}} /\left(m_{\mathrm{P}, \mathrm{RZ}}+m_{\mathrm{F}, \mathrm{RZ}}\right)
$$

In writing Eq. (31a), it is realized that although products and fuel are continuously entering the recirculation zone, an equal amount of mass per second of fully mixed gas must be leaving. Two entrainment parameters are defined as

$$
\varepsilon_{1}=m_{\mathrm{P}, \mathrm{RZ}} / m_{P} \quad \varepsilon_{2}=m_{\mathrm{F}, \mathrm{RZ}} / m_{F}
$$

so that Eq. (31b) becomes

$$
Y_{\mathrm{P}, \mathrm{RZ}}=\left[1+\left(\varepsilon_{2} / \varepsilon_{1}\right)\left(m_{F} / m_{P}\right)\right]^{-1}
$$

Conservation of mass requires that the mass flow rate of product $m_{\mathrm{P}, \mathrm{SH}}$ produced in the shear layer over the distance from $x=0$ to $L_{\mathrm{RZ}}$ equals the sum of the fuel and air mass flow rate entrained into the shear layer over that distance.

$$
m_{\mathrm{P}, \mathrm{SH}}=m_{\mathrm{F}, \mathrm{SH}}+m_{\mathrm{A}, \mathrm{SH}}
$$

In the shear layer the fuel and air are consumed in the stoichiometric proportion $r_{s}$ so that

$$
m_{\mathrm{F}, \mathrm{SH}}=m_{\mathrm{A}, \mathrm{SH}} r_{s}
$$

The characteristic air mass flow rate $m_{A}$ was defined by Eq. (3) to be $0.01 \rho_{A} U_{A} H W$, and so Eq. (30a) is rearranged to become

$$
m_{\mathrm{A}, \mathrm{SH}}=m_{A}(0.026 / 0.01)\left(L_{\mathrm{RZ}} / H\right)
$$

The result of inserting Eqs. (34a), (34b), and (35) into Eq. (33) is

$$
Y_{\mathrm{P}, \mathrm{RZ}}=\left[1+\beta_{1}\left(L_{\mathrm{RZ}} / H\right)^{-1}\left(m_{F} / m_{A}\right)\right]^{-1}
$$

$\beta_{1}$ is $\left(\varepsilon_{2} / \varepsilon_{1}\right)(0.01 / 0.026)\left(1+r_{s}\right)^{-1}$. Note that Eq. (36) displays the correct physical trends. As the mass flow rate of fuel $m_{F}$ is increased near the rich limit, more cold fuel mixes with hot products in the recirculation zone, and Eq. (36) indicates that the mass fraction of hot products $Y_{\mathrm{P}, \mathrm{RZ}}$ decreases. 
One other quantity in Eq. (24) that must be estimated is the mixture fraction $f_{\mathrm{RZ}}$ at the lower edge of the shear layer. Many models of turbulent nonpremixed combustion employ the concept that a conserved scalar exists and there is an equilibrium state relation between the gas temperature $T$ and the mixture fraction $f$. Therefore a good assumption for fuel-rich conditions is that the mixture fraction is

$$
f=1-\left(1-f_{s}\right)\left(T-T_{F}\right) /\left(T_{\mathrm{AD}}-T_{F}\right)
$$

Equation (37) correctly indicates that for pure fuel $\left(T=T_{F}\right) f$ is 1 , and when $T=T_{\mathrm{AD}}$, $f$ equals $f_{s}$. We set $f=f_{\mathrm{RZ}}$ and $T=T_{\mathrm{RZ}}$, then replace $T_{\mathrm{RZ}}$ with the right side of Eq. (26) to yield

$$
f_{\mathrm{RZ}}=1-\left(1-f_{s}\right) Y_{\mathrm{P}, \mathrm{RZ}}
$$

In Eq. (38) one can make the approximation that $f_{s}<<1$, and so $f_{\mathrm{RZ}}$ becomes $\left(1-Y_{\mathrm{P}, \mathrm{RZ}}\right)$.

Our final result for the rich limit is obtained by combining Eqs. (4), (24), (27), (36), and (38) to yield

$$
\frac{H / U_{A}}{\tau_{\mathrm{NP}}}=\phi_{o} \quad \text { for the rich limit } \quad \phi_{0}>1
$$

where

$$
\begin{aligned}
\tau_{\mathrm{NP}}= & \frac{\alpha_{0}}{S_{0}^{2}}\left\{\left[B \frac{\left(T_{\mathrm{AD}}-T_{F}\right)}{300 \mathrm{~K}}+\frac{\left(T_{F}-T_{0 A}\right)}{300 \mathrm{~K}}\right] C+\frac{T_{0 A}}{300 \mathrm{~K}}\right\}^{-2} \\
& \times\left(\frac{p}{1 \mathrm{~atm}}\right)^{-0.6} D^{-1} \quad \text { for the rich limit } \quad \phi_{0}>1
\end{aligned}
$$

Quantities $B, C$, and $D$ are defined by Eqs. (8) and (9). Finally, the left side of Eq. (39) is defined by Eq. (5) to be the Damkohler number $D_{\mathrm{NP}}$, and so inverting Eq. (39) leads to

$$
D a_{\mathrm{NP}}^{-1}=\phi_{o}^{-1} \quad \text { for the rich limit } \quad \phi_{0}>1
$$

Equation (40b) is identical to Eq. (11), which was shown to be a reasonable curve fit to the experimental data in Fig. 5.

Note that Eq. (39) predicts that $H$ should increase as $\phi_{0}$ increases. This means that as the fuel mass flow rate increases toward the rich limit the required step height $H$ increases until it exceeds the actual step height, and the flame will blow out. The physical reason for blowout is that the addition of cold fuel, which replaces hot products in the recirculation zone, causes a reduction in the mass fraction of hot products $Y_{\mathrm{P}, \mathrm{RZ}}$ and the gas temperature ahead of the flame. This lowers the burning velocity of the flame until it no longer can find a gas velocity low enough for stabilization. However, if the air stagnation temperature, fuel temperature, or adiabatic flame temperature is increased, this reduces the required step height that is calculated using Eq. (39). Replacing hydrocarbon fuel with hydrogen increases $S_{0}$, and so a smaller step is needed. All of the trends calculated using Eq. (39) are in agreement with the measurements described in the preceding section. The analysis also agrees with the experimental observation ${ }^{9,12}$ that increasing the fuel flow rate forces the flame liftoff position to move downstream until it approaches $L_{\mathrm{RZ}}$ and blowout occurs.

\section{Lean Blowout Limit-Derivation of the Flame Timescale $\tau_{\mathrm{NP}}$}

Images of flame blowout ${ }^{9,12}$ indicate that the lean blowout limit differs from the rich limit in the following way. Near the rich limit, the flame base moves downstream as the fuel flow rate is increased and fuel begins to fill the cavity. However, near the lean limit the fuel flow rate is decreasing, which forces the flame length to become much smaller, which tends to move the flame upstream and closer to the fuel injector. Two possible lean blowout regimes have been observed $^{9}$; sometimes the flame appears to be anchored within the recirculation zone, and sometimes it is anchored in the shear layer. To provide some explanation of the complex process of lean flame blowout, we consider only flames that are anchored in the shear

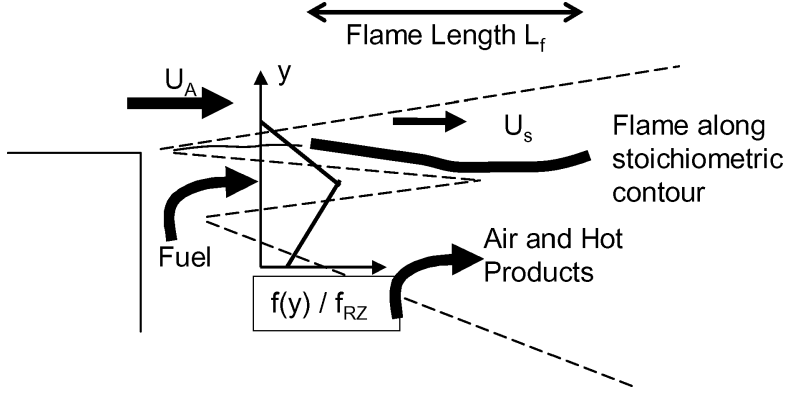

Fig. 8 Physical explanation of the lean blowout limit. The upper shear layer represents mixing between fuel and the freestream air; mixing in the lower shear is between fuel and the air/hot product gases from the recirculation zone. Decreasing the fuel flow rate reduces the length of the flammable zone $L_{f}$, which moves the flame base upstream until its propagation velocity is less than the oncoming gas velocity and lean blowout occurs.

layer, and represent them by the simplified shear layers shown in Fig. 7. In the upper shear layer the freestream air mixes with the fuel, while in the lower shear layer the recirculated products and air mix with the fuel. The length of the fuel zone (denoted $L_{f}$ in Fig. 8) is estimated to be the length of a planar fuel jet surrounded by air, which is well-known and is given by ${ }^{45}$

$$
L_{f}=c_{3} m_{F} /\left(\rho_{F} D_{T}\right)
$$

The turbulent diffusivity $D_{T}$ is proportional to the product of velocity fluctuations and a mixing length; this product is proportional to $U_{A} \delta_{A}$, so that

$$
D_{T}=c_{4} U_{A} \delta_{A}
$$

It is assumed that there is similarity between the following profiles in the nonreacting flow upstream of the flame base in the upper shear layer:

$$
\frac{f_{S}}{f_{\mathrm{CL}}}=\frac{U_{A}-U_{S}}{U_{A}-U_{\mathrm{CL}}}=\frac{T_{0}-T_{0 A}}{T_{\mathrm{CL}}-T_{0 A}}
$$

$U_{\mathrm{CL}}$ is the velocity on the jet centerline. Because $U$ varies from $U_{A}$ to zero across the two shear layers and because the jet centerline is halfway between the upper and lower shear layers, we approximate $U_{\mathrm{CL}}$ as $U_{A} / 2$. It is assumed that the lean limit occurs when the flame base moves upstream to approximately $x=0$. At this condition the length of the fuel jet is small, and so a good approximation is that $f_{\mathrm{CL}}=1$. Thus Eq. (43) becomes

$$
U_{s}=U_{A}\left(1-f_{s} / 2\right) \Gamma
$$

where $\Gamma$ was assumed in the preceding section to be equal to the value of $\Gamma$ in a lifted jet flame, which is $c_{1}\left[\left(\alpha / S_{\text {base }}\right) / x\right]$. The flame liftoff height $h$ is the $x$ location, where the gas velocity and flame propagation velocity are matched, and so we set $U_{s}=S_{\text {base }}$ and $x=h$ to obtain

$$
h=U_{A}\left(1-f_{s} / 2\right)\left(c_{1} \alpha / S_{\text {base }}^{2}\right)
$$

$L_{f}$ is defined as the length of the flammable zone seen in Fig. 7; downstream of $x=L_{f}$ there is so much air present that the mixture is not flammable. We also have defined $h$ to be the $x$ location on the stoichiometric contour, where the gas velocity is sufficiently low that it is matched to the propagation speed of the flame base. Therefore the flame cannot be stabilized if the length of the flammable region becomes less than the liftoff height, and so lean blowout occurs at the limiting condition:

$$
h=L_{f}
$$

Now Eqs. (41-46) are combined; $U_{A}$ is replaced with $m_{A} /\left(0.01 \rho_{A} H W\right)$ using the definition of $m_{A}$ [Eq. (3)]. $D_{T}$ is replaced with the right side of Eq. (42), and $S_{\text {base }}$ and $\alpha$ are replaced 
by Eqs. (22) and (23). With these substitutions, the nondimensional step height required at the lean limit becomes

$$
\left(\frac{H / U_{A}}{\alpha_{0} / S_{0}^{2}}\right)=\left(\frac{m_{F}}{m_{A}}\right)^{-1}\left[\frac{T_{S}}{300 \mathrm{~K}}\right]^{-2}\left(\frac{p}{1 \mathrm{~atm}}\right)^{-0.6}\left(1-\frac{f_{s}}{2}\right) c_{5}
$$

where $c_{5}$ is $(\ell / W)\left(c_{1} c_{4}\right) /\left(0.01 c_{3}\right)\left(\rho_{F} / \rho_{A}\right)$. In the upper shear layer (upstream of any reaction) the mixture fraction and temperature profiles are similar, and so Eq. (43) can be rearranged to be

$$
T_{s}=T_{0 A}+\left(T_{\mathrm{CL}}-T_{0 A}\right)\left(f_{s} / f_{\mathrm{CL}}\right)
$$

$T_{\mathrm{CL}}$ is the temperature on the fuel jet centerline. We also assume that the temperature in the lower shear layer varies linearly in the $y$ direction, so that $T_{\mathrm{CL}}=\left(T_{\mathrm{RZ}}+T_{0 A}\right) / 2$. Because the recirculation zone consists of products and air near the lean limit, the enthalpy balance is

$$
c_{p} T_{\mathrm{RZ}}=Y_{\mathrm{P}, \mathrm{RZ}} c_{p} T_{\mathrm{AD}}+\left(1-Y_{\mathrm{P}, \mathrm{RZ}}\right) c_{p} T_{0 A}
$$

The mass fraction of products in the RZ depends on the mass flow rate of products and air into the $\mathrm{RZ}$ according to

$$
Y_{\mathrm{P}, \mathrm{RZ}}=m_{\mathrm{P}, \mathrm{RZ}} /\left(m_{\mathrm{P}, \mathrm{RZ}}+m_{\mathrm{A}, \mathrm{RZ}}\right)
$$

We now define two new entrainment parameters:

$$
\varepsilon_{3}=m_{\mathrm{A}, \mathrm{RZ}} / m_{\mathrm{A}, \mathrm{SH}} \quad \varepsilon_{4}=m_{\mathrm{F}, \mathrm{SH}} / m_{F}
$$

Replacing the quantities in Eq. (50) using Eqs. (30) and (51) results in

$$
Y_{\mathrm{P}, \mathrm{RZ}}=\left[1+\left(\varepsilon_{3} / \varepsilon_{1}\right)(0.026 / 0.01)\left(L_{\mathrm{RZ}} / H\right)\left(m_{A} / m_{P}\right)\right]^{-1}
$$

Conservation of mass requires that the mass flow rate of products produced in the shear layer $m_{\mathrm{P}, \mathrm{SH}}$ equals $m_{\mathrm{F}, \mathrm{SH}}+m_{\mathrm{A}, \mathrm{SH}}$; the stoichiometric fuel-air ratio $r_{s}$ is $m_{\mathrm{F}, \mathrm{SH}} / m_{\mathrm{A}, \mathrm{SH}}$ so it follows that

$$
m_{P}=m_{\mathrm{F}, \mathrm{SH}}\left(1+r_{s}^{-1}\right)=\varepsilon_{4} m_{F}\left(1+r_{s}^{-1}\right)
$$

The last two equations result in

$$
Y_{\mathrm{P}, \mathrm{RZ}}=\left[1+\beta_{3}\left(L_{\mathrm{RZ}} / H\right)\left(m_{F} / m_{A}\right)^{-1}\right]^{-1}
$$

where $\beta_{3}$ is $\left[\varepsilon_{3} /\left(\varepsilon_{1} \varepsilon_{4}\right)\right](0.026 / 0.01)\left(1+r_{s}^{-1}\right)^{-1}$. Equation (54) indicates that if the fuel flow rate $m_{F}$ is decreased near the lean limit fewer hot products are formed, so that the mass fraction of products in the RZ decreases. This reduces the temperature $T_{s}$ and the flame speed.

Our result for the lean limit is obtained by combining Eqs. (47-49) and (54)

$$
D a_{\mathrm{NP}}^{-1}=\left(\frac{H / U_{A}}{\tau_{\mathrm{NP}}}\right)^{-1}=\phi_{o} \quad \text { for the lean limit } \quad \phi_{0}<1
$$

where

$$
\begin{aligned}
\tau_{\mathrm{NP}}= & \frac{\alpha_{0}}{S_{0}^{2}}\left[A \frac{\left(T_{\mathrm{AD}}-T_{0 A}\right)}{300 \mathrm{~K}} \frac{f_{s}}{2}+\frac{T_{0 A}}{300 \mathrm{~K}}\right]^{-2}\left(\frac{p}{1 \mathrm{~atm}}\right)^{-0.6} \\
& \times r_{s}^{-1}\left(\frac{H}{W}\right) \beta_{4}^{-1} \quad \text { for the lean limit }
\end{aligned}
$$

These are the same relations as Eqs. (6a) and (10) that were successfully used to correlate the data. Combining the preceding equa- tions also leads to a relation for the quantity $A$ that is given by Eq. (11a) and to a relation for $\beta_{4}$ that is $\left[\left(0.01 c_{3}\right) /\left(c_{1} c_{4}\right)\right]\left[\rho_{A} /\right.$ $\left.\rho_{F}\right)[H / \ell]\left[1-f_{s} / 2\right]^{-1}$.

Our result [Eqs. (55) and (56)] correctly indicates that as the fuel flow rate (and thus $\phi_{0}$ ) are decreased near the lean limit, the minimum step height $H$ increases. The equations also indicate that a larger step height also is required if the pressure, the air temperature, or the adiabatic flame temperature is decreased, which is in agreement with experiments.

\section{Conclusions}

1) Approximately 100 values of flame blowout limits were tabulated that were measured in six previous studies of nonpremixed flames stabilized in high-speed airstreams. An analysis was performed to identify the relevant Damkohler number and flame timescale $\tau_{\mathrm{NP}}$ for nonpremixed conditions. The analysis is based on the assumption that the flame base exists in the shear layer and has a propagation speed that is matched to the local gas velocity. Using the Damkohler number of our analysis, it was found that the high-speed, nonpremixed flame data could be adequately correlated. Previously such a correlation has been reported only for relatively low-speed premixed flames.

2) The analysis correctly predicts the measured trends associated with changes in the fuel flow rate, air stagnation temperature, and gas pressure. It shows that the stoichiometric fuel-air ratio $f_{s}$ is important because it determines the distance between the stoichiometric contour and the high-speed airstream. It also provides a useful definition of the overall fuel-air equivalence ratio for nonpremixed conditions, which is consistent with previous studies of entrainment rates into recirculation zones.

3) Several differences between nonpremixed and premixed flame stabilization are discussed. In the nonpremixed case the location of fuel injection is important; if too much fuel is injected, the recirculation zone becomes "flooded" with fuel and rapidly cools, leading to rich blowout.

4) The analysis avoids an assumption that has been used in previous work, which requires that the residence time of a mixture of fuel and air in the recirculation zone be matched to a chemical reaction time associated with a homogeneous fuel-air mixture in the recirculation zone. Recent experiments by Kalt et al. show that fuel and air do not coexist in the recirculation zone for their conditions. The new features of the analysis are that a) fuel and air do not coexist and react in the recirculation zone, but hot products coexist with fuel near the rich limit and products and air coexist near the lean limit; b) reactions occur in the shear layer, not the recirculation zone; and c) blowout is governed by the imbalance between the flame propagation speed and the gas velocity that occurs near the stoichiometric contour.

5) The analysis demonstrates that additional research is needed to quantify entrainment rates, the temperature and species concentrations in the recirculation zone, and the flow path taken by the fuel from the injector to the shear layer. The poorest correlation of blowout limits occurred when fuels are used that have large differences in burning velocity, such as hydrogen and methane. This suggests that the chemical time might not scale as square of the burning velocity, which has been assumed in the past.

\section{Appendix: Mixture Properties}

Table A1 Properties of different fuel-air mixtures

\begin{tabular}{lcccc}
\hline \hline Mixture & $S_{0}, \mathrm{~cm} / \mathrm{s}^{\mathrm{a}}$ & $f_{s}{ }^{\mathrm{b}}$ & $r_{s}{ }^{\mathrm{c}}$ & $T_{\mathrm{AD}}-T_{0 A}, \mathrm{~K}^{\mathrm{d}}$ \\
\hline Hydrogen-air & 210 & 0.028 & 0.029 & 2018 \\
Ethylene-air & 73 & 0.064 & 0.068 & 1952 \\
Methane-air & 43 & 0.055 & 0.058 & 1848 \\
Propane-air & 43 & 0.06 & 0.064 & 1908 \\
\hline \hline
\end{tabular}

${ }^{\text {a }} S_{0}=$ stoichiometric laminar burning velocity at $300 \mathrm{~K}, 1 \mathrm{~atm}$.

${ }^{\mathrm{b}} f_{s}=$ stoichiometric mixture fraction (defined in Ref. 33).

${ }^{\mathrm{c}} r_{s}=$ stoichiometric fuel-air ratio.

${ }^{\mathrm{d}} T_{\mathrm{AD}}=$ adiabatic flame temperature. 


\section{Acknowledgments}

This work was supported by funds from NASA and from the U.S. Air Force for the Constellation University Institutes Project, which funds the Space Vehicle Technology Institute, a portion of which is located at the University of Michigan. The authors benefited from previous collaboration with researchers at the U.S. Air Force Wright Laboratories (J. M. Donbar, C. D. Carter, K.-Y. Hsu, M. R. Gruber).

\section{References}

${ }^{1}$ Zukoski, E. E., and Marble, F. E., "Experiments Concerning the Mechanism of Flame Blowoff from Bluff-Bodies," Proceedings of the Gas Dynamics Symposium on Thermochemistry, Northwestern Univ., Evanston, IL, 1956, pp. 205-225.

${ }^{2}$ Ozawa, R. I., "Survey of Basic Data on Flame Stabilization and Propagation for High Speed Combustion Systems," U.S. Air Force, AFAPL Technical Rept. TR-70-81, Wright-Patterson AFB, OH, Jan. 1971.

${ }^{3}$ Plee, S. L., and Mellor, A. M., "Characteristic Time Correlation for Lean Blowoff of Bluff-Body Stabilized Flames," Combustion and Flame, Vol. 35, No. 1, 1979, pp. 61-80.

${ }^{4}$ Kundu, K., Banerjee, D., and Bhaduri, D., "Theoretical Analysis on Flame Stabilization by a Bluff-Body," Combustion Science and Technology, Vol. 17, No. 1, 1977, pp. 153-162.

${ }^{5}$ Baxter, M. R., and Lefebvre, A. H., "Flame Stabilization in High-Velocity Heterogeneous Fuel-Air Mixtures," Journal of Propulsion and Power, Vol. 8 , No. 6, 1992, pp. 1138-1143.

${ }^{6}$ Winterfeld, G., "On the Process of Turbulent Exchange Behind Flame Holders," Proceedings of the Combustion Institute, Vol. 10, 1965, pp. $1265-1275$.

${ }^{7}$ Winterfeld, G., "Investigations on the Stabilization of Hydrogen Diffusion Flames in Supersonic Flow," Deutschen Forshungs-und Versuchsanstalt fur Luft und Raumfahrt, Rept. FB-76-35, Porz-Wahn, Germany, Sept. 1976.

${ }^{8}$ Gruber, M. R., Baurle, R. A., Mathur, T., and Hsu, K.-Y., "Fundamental Studies of Cavity-Based Flameholder Concepts for Supersonic Combustors," Journal of Propulsion and Power, Vol. 17, No. 1, 2001, pp. 146-153.

${ }^{9}$ Rasmussen, C. C., Driscoll, J. F., Hsu, K.-Y., Donbar, J. M., Gruber, M. R., and Carter, C. D., "Stability Limits of Cavity-Stabilized Flames in Supersonic Flows," Proceedings of the Combustion Institute, Vol. 30, The Combustion Institute, Pittsburgh, PA, 2005, pp. 2825-2831.

${ }^{10}$ Gruber, M. R., Donbar, J. M., Carter, C. D., and Hsu, K.-Y., "Mixing and Combustion Studies Using Cavity-Based Flameholders in a Supersonic Flow," Journal of Propulsion and Power, Vol. 20, No. 5, 2004, pp. 769-778.

${ }^{11}$ Ben-Yakar, A., and Hanson, R. K., "Cavity Flame-Holders for Ignition and Flame Stabilization in Scramjets: An Overview," Journal of Propulsion and Power, Vol. 17, No. 4, 2001, pp. 869-877.

${ }^{12}$ Rasmussen, C. C., Driscoll, J. F., Carter, C. D., and Hsu, K.-Y., "Characteristics of Cavity-Stabilized Flames in a Supersonic Flow," Journal of Propulsion and Power, Vol. 21, No. 4, 2005, pp. 765-768.

${ }^{13}$ Niioka, T., Terada, K., Kobayashi, H., and Hasegawa, S., "Flame Stabilization Characteristics of a Strut Divided into Two Parts in Supersonic Airflow," Journal of Propulsion and Power, Vol. 11, No. 1, 1995, pp. 112-115.

${ }^{14}$ Northam, G. B., Trexler, C. A., and McClinton, C., "Flame-Holding Characteristics of a Swept Strut Hydrogen Fuel Injector for Scramjet Application," NASA TR A81-10711, Jan. 1981.

${ }^{15}$ Yoon, Y., Donbar, J. M., and Driscoll, J. F., "Blowout Stability Limits of a Hydrogen Jet Flame in a Supersonic, Heated Coflowing Air Stream," Combustion Science and Technology, Vol. 97, No. 1, 1994, pp. 137-156.

${ }^{16}$ Huh, H., and Driscoll, J. F., "Shock-Wave Enhancement of the Mixing and Stability Limits of Supersonic Hydrogen-Air Jet Flames," Proceedings of the Combustion Institute, Vol. 26, The Combustion Institute, Pittsburgh, PA, 1996, pp. 2933-2939.

${ }^{17}$ Schefer, R. W., Namazian, M., Kelly, J., and Perrin, M., "Effect of Confinement on Bluff-Body Burner Recirculation Zone Characteristics and Flame Stability," Combustion Science and Technology, Vol. 120, No. 1, 1996, pp. 185-211.

${ }^{18}$ Owens, M., Mullagiri, S., and Segal, C., "Effects of Fuel Preinjection on Mixing in Mach 1.6 Airflow," Journal of Propulsion and Power, Vol. 17, No. 3, 2001, pp. 605-610.

${ }^{19}$ Owens, M. G., Tehranian, S., and Segal, C., "Flame-Holding Configurations for Kerosene Combustion in a Mach 1.8 Airflow," Journal of Propulsion and Power, Vol. 14, No. 4, 1998, pp. 456-461.

${ }^{20}$ Bovina, T. A., "Studies of Exchange Between Re-Circulation Zone Behind the Flame-Holder and Outer Flow," Proceedings of the Combustion Institute, Vol. 7, The Combustion Institute, Pittsburgh, PA, 1959, pp. 692-704.

${ }^{21}$ Hsu, K.-Y., Goss, L. P., and Roquemore, W. M., "Characteristics of a Trapped-Vortex Combustor," Journal of Propulsion and Power, Vol. 14,
No. 1, 1998, pp. 57-65.

${ }^{22}$ Katta, V. R., and Roquemore, W. M., "Study on Trapped Vortex Combustor-Effect of Injection on Flow Dynamics," Journal of Propulsion and Power, Vol. 14, No. 3, 1998, pp. 273-281.

${ }^{23}$ Feikema, D., Chen, R.-H., and Driscoll, J. F., "Enhancement of Flame Blowout Limits by the Use of Swirl," Combustion and Flame, Vol. 80, No. 1, 1990, pp. 183-195.

${ }^{24}$ Feikema, D., Chen, R.-H., and Driscoll, J. F., "Blowout of Nonpremixed Flames: Maximum Coaxial Air Velocities Achievable, with and Without Swirl," Combustion and Flame, Vol. 86, No. 2, 1991, pp. 347-358.

${ }^{25}$ Rawe, R., and Kremer, H., "Stability Limits of Natural Gas Diffusion Flames with Swirl," Proceedings of the Combustion Institute, Vol. 18, The Combustion Institute, Pittsburgh, PA, 1981, pp. 667-677.

${ }^{26}$ Donbar, J. M., Driscoll, J. F., and Carter, C. D., "Reaction Zone Structure in Turbulent Nonpremixed Jet Flames-From CH-OH PLIF Images," Combustion and Flame, Vol. 122, No. 1, 2000, pp. 1-19.

${ }^{27}$ Namazian, M., Kelly, J. T., and Schefer, R. W., "Near Field Instantaneous Flame and Fuel Concentration Structures," Proceedings of the Combustion Institute, Vol. 22, The Combustion Institute, Pittsburgh, PA, 1988, pp. 627-634.

${ }^{28}$ Schefer, R. W., Namazian, M., and Kelly, J., "CH, OH, and $\mathrm{CH}_{4}$ Concentration Measurements in a Lifted Turbulent Jet Flame," Proceedings of the Combustion Institute, Vol. 23, The Combustion Institute, Pittsburgh, PA, 1990, pp. 669-676.

${ }^{29}$ Schefer, R. W., Namazian, M., and Kelly, J., "Stabilization of Lifted Turbulent-Jet Flames," Combustion and Flame, Vol. 99, No. 1, 1994, pp. $75-86$.

${ }^{30}$ Vanquickenborne, L., and van Tiggelen, A., "The Stabilization Mechanism of Lifted Diffusion Flames," Combustion and Flame, Vol. 10, No. 1, 1966, pp. 59-72.

${ }^{31}$ Upatnieks, A., Driscoll, J. F., and Ceccio, S. L., "Cinema PIV Time History of the Propagation Velocity of the Base of a Lifted Turbulent Jet Flame," Proceedings of the Combustion Institute, Vol. 29, The Combustion Institute, Pittsburgh, PA, 2002, pp. 1898-1903.

${ }^{32}$ Muniz, L., and Mungal, M. G., "Instantaneous Flame-Stabilization Velocities in Lifted Jet Diffusion Flames," Combustion and Flame, Vol. 111, No. 1, 1997, pp. 16-31.

${ }^{33}$ Kalt, P. A, Al-Abdeli, Y. M., Masri, A. R., and Barlow, R. S., "Swirling Turbulent Non-Premixed Flames of Methane: Flow Field and Compositional Structure," Proceedings of the Combustion Institute, Vol. 29, The Combustion Institute, Pittsburgh, PA, 2002, pp. 1913-1919.

${ }^{34}$ Ratner, A., Driscoll, J. F., Donbar, J. M., Carter, C. D., and Mullin, J. A., "Reaction Zone Structure of Non-Premixed Turbulent Flames in the 'Intensely Wrinkled' Regime," Proceedings of the Combustion Institute, Vol. 28, The Combustion Institute, Pittsburgh, PA, 2000, pp. 245-252.

${ }^{35}$ Papamoschou, D., and Roshko, A., "The Compressible Turbulent Shear Layer: An Experimental Study," Journal of Fluid Mechanics, Vol. 197, 1988, pp. 453-477.

${ }^{36}$ Chen, Y.-C., and Bilger, R. W., "Stabilization Mechanisms of Lifted Laminar Flames in Axisymmetric Jet Flows," Combustion and Flame, Vol. 123, No. 1, 2000, pp. 23-45.

${ }^{37}$ Upatnieks, A., Driscoll, J. F., Rasmussen, C. C., and Ceccio, S. L., "Liftoff of Turbulent Jet Flames-Assessment of Edge Flame and Other Concepts Using Cinema-PIV Diagnostics," Combustion and Flame, Vol. 138, No. 3, 2004, pp. 259-272.

${ }^{38}$ Boulanger, J., Vervisch, R., and Ghosal, S., "Effects of Heat Release in Laminar Diffusion Flames Lifted on Round Jets," Combustion and Flame, Vol. 134, No. 3, 2003, pp. 355-368.

${ }^{39}$ Kalghatgi, G., "Liftoff Heights and Visible Lengths of Vertical Turbulent Jet Diffusion Flames in Still Air," Combustion Science and Technology, Vol. 41, No. 1, 1984, pp. 17-29.

${ }^{40}$ Kalghatgi, G., "Blow-Out Stability of Gaseous Jet Diffusion Flames in Still Air," Combustion Science and Technology, Vol. 26, No. 3, 1981, pp. 233-239.

${ }^{41}$ Iijima, T., and Takeno, T., "Effects of Temperature and Pressure on Burning Velocity," Combustion and Flame, Vol. 65, No. 1, 1986, pp. 35-43.

${ }^{42}$ Muller, U. C., Bollig, M., and Peters, N., "Approximations for Burning Velocities and Markstein Numbers for Lean Hydrocarbons and Methanol Flames," Combustion and Flame, Vol. 108, No. 3, 1997, pp. 349-356.

${ }^{43}$ Gulder, O. L., "Laminar Burning Velocities of Methanol, Ethanol, and Isooctane-Air Mixtures," Proceedings of the Combustion Institute, Vol. 19, The Combustion Institute, Pittsburgh, PA, 1982, pp. 275-281.

${ }^{44}$ Slessor, M. D., Zhuang, M., and Dimotakis, P. E., "Turbulent ShearLayer Mixing: Growth-Rate Compressibility Scaling," Journal of Fluid Mechanics, Vol. 414, 2000, pp. 35-45.

${ }^{45}$ Glassman, I., Combustion, 2nd ed., Academic Press, New York, 1987, p. 254 . 